\title{
The effects of erythropoietin on RhoA/Rho-associated kinase expression in rat retinal explants cultured with glutamate
}

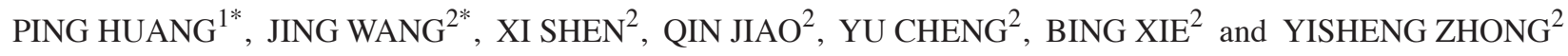 \\ ${ }^{1}$ Shanghai Institute of Traumatology and Orthopaedics; ${ }^{2}$ Department of Ophthalmology, \\ Ruijin Hospital Shanghai Jiao Tong University School of Medicine, Shanghai 200025, P.R. China
}

Received March 6, 2012; Accepted June 6, 2012

DOI: $10.3892 / \mathrm{mmr} .2012 .947$

\begin{abstract}
The aim of this study was to investigate the effects of erythropoietin (EPO) on RhoA/Rho-associated kinase (ROCK) expression in rat retinal explants cultured with glutamate. After the retinal explants were cultured in serumfree R16 nutrient medium for $24 \mathrm{~h}$, the retinal explants were divided into control (R16 nutrient medium), glutamate (R16 nutrient medium containing $5 \mathrm{mM} / 1$ glutamate) and glutamate + EPO (R16 nutrient medium containing $5 \mathrm{mM} / 1$ glutamate and $6.0 \mathrm{U} / \mathrm{ml} \mathrm{EPO}$ ) groups, and culturing was continued for another $72 \mathrm{~h}$. The mRNA and protein expression of total RhoA, ROCK 1 and ROCK 2 in the retinal explants was examined by RT-PCR and western blotting, and active RhoA in the retinal explants was detected via GST-RBD binding and immunoblotting with an antibody specific to active RhoA. The total RhoA mRNA and protein expression did not differ substantially between the control, the glutamate and the glutamate + EPO groups. The glutamate increased the active RhoA, ROCK1 and ROCK2 expression in cultured retinal explants $(\mathrm{P}<0.05)$, whereas the expression of active RhoA, ROCK1 and ROCK2 in the glutamate + EPO group was significantly lower than that in the simple glutamate group $(\mathrm{P}<0.05)$ and similar to that in the control group. In conclusion, EPO downregulates active RhoA, ROCK1 and ROCK2 expression in retinal explants cultured with glutamate.
\end{abstract}

\section{Introduction}

Rho-associated kinase (ROCK) is a serine/threonine kinase and one of the major downstream effectors of the small GTPase

Correspondence to: Dr Yisheng Zhong or Dr Bing Xie, Department of Ophthalmology, Ruijin Hospital, Shanghai Jiao Tong University School of Medicine, 197 Rui Jin Er Road, Shanghai 200025, P.R. China

E-mail: yszhong68@yahoo.com.cn

E-mail: bingxie1@gmail.com

*Contributed equally

Key words: erythropoietin, RhoA, Rho-associated kinase, retinal explants, glutamate
RhoA. The RhoA/ROCK pathway is closely correlated with the pathogenesis of several central nervous system (CNS) disorders and is involved in a number of aspects of neuronal functions, including neurite outgrowth and retraction (1). The effects of these axon growth inhibitors are reversed by blocking the RhoA/ROCK pathway in vitro (2-4), and inhibition of the RhoA/ROCK pathway promotes axon regeneration and functional recovery in the injured CNS in vivo $(2,5,6)$.

Erythropoietin (EPO) has been found to act on the CNS as a neurotrophic and neuroprotective factor, particularly in conditions of neural damage, such as hypoxia, ischemia or brain hemorrhage (7-10). Previous studies in animal models have indicated that EPO is effective in enhancing neurological recovery following experimental spinal cord injury (11-13). EPO has also been shown to protect retinal ganglion cells (RGCs) in rat models of glaucoma $(14,15)$, axotomy-induced degeneration $(16,17)$ and retinal ischemia (18) and to promote the axonal regeneration of RGCs following optic nerve transection (19). Previous studies also showed that there is crosstalk between hypoxia inducible factor-1 (HIF-1) and the ROCK pathways in neuronal differentiation of mesenchymal stem cells, neurospheres and in PC12 neurite outgrowth (20), and that EPO is one of the major target genes of HIF-1. Therefore, crosstalk may also exist between EPO and the RhoA/ROCK pathway. There are, however, few data available concerning the effects of EPO on the RhoA/ROCK pathway. Therefore, the aim of the present study was to clarify whether EPO regulates the RhoA/ROCK protein expression in rat retinal explants cultured with glutamate.

\section{Materials and methods}

Animals. Animals included in this study were treated in accordance with the ARVO Statement for the Use of Animals in Ophthalmic and Vision Research. In addition, the Ethics Committee of Ruijin Hospital (Shanghai, China) approved the experiments. Sprague-Dawley (SD) rat pups were used in all experiments, kept under conditions of constant temperature and humidity and fed by their mothers. The day of birth was counted as postnatal day (P)0 and P2-3 rats were used in our experiment. A total of 150 rats was used for this study.

Retinal explant dissection. The SD rats were sacrificed on P2-3 by decapitation. Tissue soaked in $70 \%$ ethanol was used 
to wipe clean and wrap the removed heads. The wrapped heads were transported into a culture room to a laminar flow cabinet from which point onwards all handling was performed aseptically. The eyes were enucleated and incubated in serumfree R16 nutrient medium. The anterior segment, vitreous body and sclera were then removed and the retinal explants were collected. Approximately 20 eyes were collected for each experiment.

Retinal explant culture. The complete list of chemicals making up the originally developed R16 nutrient medium for brain tissue (Gibco/BRL, Carlsbad, CA, USA) has been published previously $(21,22)$. The $\mathrm{R} 16$ powder is composed of 41 ingredients that can be divided into three groups: group 1 consisted of salts; group 2 included the amino acids with the exception of the potentially neurotoxic amino acids glutamate and aspartate; and group 3 included sugars and vitamins. The retinal explants were cultured in 12-well culture plates with serum-free R16 nutrient medium. Each well contained 4 retinal explants which were cultured in a humidified incubator at $37^{\circ} \mathrm{C}$ in an atmosphere of $5 \% \mathrm{CO}_{2}-95 \% \mathrm{O}_{2}$.

Drug treatment. EPO was prepared by dissolving $10 \mu \mathrm{g}$ EPO (R\&D Systems, Minneapolis, MN, USA) in $200 \mu \mathrm{l}$ distilled water $(8.3 \mu \mathrm{g}=1,000$ units EPO). The retinal explants were cultured for $24 \mathrm{~h}$ as described above and then divided into three groups: the control, glutamate and glutamate + EPO groups. The retinal explants in the control group were continually cultured with serum-free R16 nutrient medium; the retinal explants in the glutamate group were continually cultured with serum-free R16 nutrient medium containing $5 \mathrm{mM} / 1$ glutamate (Sigma-Aldrich, St. Louis, MO, USA); and the retinal explants in the glutamate + EPO group were continually cultured with serum-free R16 nutrient medium containing $5 \mathrm{mM} / 1$ glutamate and $6.0 \mathrm{U} / \mathrm{ml}$ EPO. The retinal explants in the three groups were continually cultured for another $72 \mathrm{~h}$. The doses of glutamate and EPO used in the present study were selected according to our previous study in which it was shown that $6.0 \mathrm{U} / \mathrm{ml}$ EPO significantly improved the survival of cultured retinal neurocytes incubated with $5 \mathrm{mM} / \mathrm{l}$ glutamate (23).

Reverse transcription-polymerase chain reaction (RT-PCR). The mRNA levels of the genes were measured by RT-PCR. Total RNA was isolated from the individual samples using the TRIzol ${ }^{\circledR}$ reagent (Invitrogen, Carlsbad, CA, USA). The concentration and purity of the preparations were determined by measuring the absorbance at $260 / 280 \mathrm{~nm}$ using a spectrophotometer (Beckman Coulter, Miami, FL, USA). Total RNA was reverse-transcribed into cDNA in a 20- $\mu$ l reaction volume containing $2 \mu \mathrm{g}$ RNA, $4 \mu \mathrm{l}$ 5X M-MLV buffer, $2 \mu \mathrm{l} \mathrm{dNTP}$, $1 \mu \mathrm{l}$ random hexamer primer, $0.5 \mu \mathrm{l}$ RNase inhibitor and $1 \mu \mathrm{l}$ M-MLV RTase. The reactions were performed at $25^{\circ} \mathrm{C}$ for $10 \mathrm{~min}$, at $42^{\circ} \mathrm{C}$ for $60 \mathrm{~min}$ and at $70^{\circ} \mathrm{C}$ for $10 \mathrm{~min}$.

The nucleotide sequences of the primers were based on previously published sequences $(24,25)$. The primer sequences used for RT-PCR were: RhoA, 5'-GTGATTGTTGGT GATGGAGC-3' and 5'-CTCGTGGCCATCTCAAAAAC-3'; ROCK-1, 5'-TGCGGGAGTTACAAGATCAGCT-3' and 5'-TTTCCGTCAGTCTCATCAGCAC-3'; ROCK-2, 5'-TCTG
AAAGGAGGGACCGAACC-3' and 5'-GTTCCTGTTT GTGTCGAGCCATCA-3'; glyceraldehyde 3-phosphate dehydrogenase (GAPDH), 5'-ATGGGGAAGGTGAAGGTCGG-3' and 5'-CAGGAGGCATTGCTGATGAT-3'. The PCR protocol comprised an initial incubation for $5 \mathrm{~min}$ at $94^{\circ} \mathrm{C} ; 30$ cycles (for RhoA, ROCK-1 and ROCK-2) or 25 cycles (for GAPDH) of $45 \mathrm{sec}$ at $94^{\circ} \mathrm{C}, 45 \mathrm{sec}$ at $55^{\circ} \mathrm{C}$ and $2 \mathrm{~min}$ at $72^{\circ} \mathrm{C}$ and a final incubation for $7 \mathrm{~min}$ at $72^{\circ} \mathrm{C}$. The PCR products were separated by $2 \%$ agarose gel electrophoresis and stained with $0.5 \mu \mathrm{g} / \mathrm{ml}$ ethidium bromide, and the band signals were exposed to ultraviolet radiation before they were scanned and quantified with a gel image analyzer (GelDoc Quantity One; Bio-Rad, Hercules, CA, USA). Band intensities were quantified and normalized against those of GAPDH. Each set of experiments was repeated in triplicate for statistical analysis.

Western blot analysis. Total retinal protein was extracted from pulverized samples using modified radioimmunoprecipitation (modified RIPA) buffer with a Halt ${ }^{\mathrm{TM}}$ protease and phosphatase inhibitor cocktail (Thermo Scientific, Rockford, IL, USA). The protein concentrations were determined by the Bradford protein assay (Bio-Rad). Each sample contained 4 retinal explants. Equal amounts of protein (20 $\mu \mathrm{g} /$ lane) were separated on polyacrylamide gels and then electrotransferred onto a nitrocellulose membrane (Amersham, Buckinghamshire, UK). After blocking for $3 \mathrm{~h}$ in Tris-buffered saline with $0.1 \%$ Tween-20 (TBST) and 3\% bovine serum albumin (BSA), the membranes were incubated overnight at $4{ }^{\circ} \mathrm{C}$ with primary antibodies (RhoA, dilution 1:50, sc-418; ROCK-1, dilution 1:50, sc-6056; ROCK-2, dilution 1:50, sc-5561; Santa Cruz Biotechnology, Inc., Santa Cruz, CA, USA) in TBST containing $3 \%$ BSA. The membranes were then washed and incubated with alkaline phosphatase-conjugated secondary antibodies in TBST for $2 \mathrm{~h}$ and developed using nitro blue tetrazolium chloride (NBT)/5-bromo-4-chloro-3-indolyl phosphate (BCIP) substrate (Promega, Madison, WI, USA). The densities of the bands on the membrane were scanned and analyzed using Image Pro Plus version 6.0 (Media Cybernetics, Silver Spring, MD, USA). Each set of experiments was repeated in triplicate for statistical analysis.

RhoA activity assay. Active RhoA was assayed in tissue lysates using a Rho activation assay kit (Upstate Biotechnology, Milton Keynes, UK), following the manufacturer's instructions as described previously $(26,27)$. Briefly, the retinal protein $(200 \mu \mathrm{g})$ was mixed with glutathione-S-transferase (GST)-Rho-binding domain (RBD) fusion protein $(20 \mu \mathrm{l})$ in an ice bath and the mixture was incubated for 45 min at $4{ }^{\circ} \mathrm{C}$ with intermittent mixing. After the mixture was centrifuged $(13,000 \mathrm{x} \mathrm{g})$ for $10 \mathrm{~min}$ at $4^{\circ} \mathrm{C}$, the precipitate was suspended with $\mathrm{Mg}^{2+}$ lysis/wash buffer $(500 \mu \mathrm{l})$ and centrifuged for $10 \mathrm{~min}$. This procedure was repeated three times. The final precipitate was used for active RhoA assay by western blot analysis. Each set of experiments was repeated in triplicate for statistical analysis.

Statistical analysis. Data were presented as the mean \pm standard deviation, unless otherwise stated. Statistical analyses were performed using the SPSS software (IBM SPSS Statistics 19.0, SPSS, Inc., Chicago, IL, USA). To compare data among 


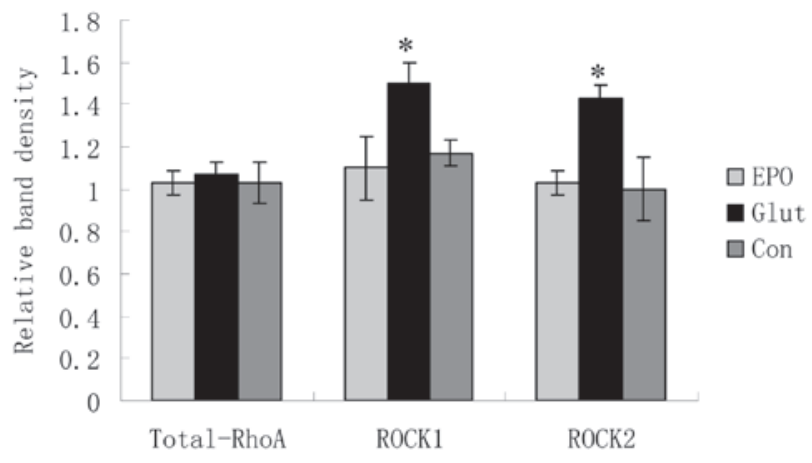

Figure 1. RT-PCR analysis of RhoA, ROCK1 and ROCK2 in retinal explants after $72 \mathrm{~h}$ culture with $5 \mathrm{mM} / 1$ glutamate and $6.0 \mathrm{U} / \mathrm{ml}$ EPO. The RhoA mRNA expression did not differ substantially between the groups. The glutamate increased ROCK1 and ROCK2 mRNA expression in cultured retinal explants. ROCK1 and ROCK2 mRNA expression in the EPO group was significantly lower than that in the simple glutamate group, and similar to that in the control group. EPO: $6 \mathrm{U} / \mathrm{ml} \mathrm{EPO}+5 \mathrm{mM} / 1$ glutamate culture group; Glut: $5 \mathrm{mM} / 1$ glutamate culture group; Con: control group. ${ }^{*} \mathrm{P}<0.05$ compared with EPO and control groups. RT-PCR, reverse transcription-polymerase chain reaction; ROCK, Rho-associated kinase; EPO, erythropoietin.

three groups, one-way analysis of variance (ANOVA) was performed followed by post hoc tests. $\mathrm{P}<0.05$ was considered to indicate a statistically significant difference.

\section{Results}

Effect of EPO on RhoA, ROCK1 and ROCK2 mRNA expression in retinal explants cultured with glutamate. RT-PCR analysis revealed that the RhoA mRNA expression did not differ substantially between the control, glutamate and glutamate + EPO groups. Compared with the control group, the glutamate increased ROCK1 and ROCK2 mRNA expression in cultured retinal explants $(\mathrm{P}<0.05$; Fig. 1). The ROCK1 and ROCK 2 mRNA expression in the glutamate + EPO group was significantly lower than that in the simple glutamate group $(\mathrm{P}<0.05$; Fig. 1) and similar to that in the control group.

Effect of EPO on RhoA, ROCK1 and ROCK2 protein expression in retinal explants cultured with glutamate. Western blot analysis revealed that the protein expression of total-RhoA did not differ substantially between the control, glutamate and glutamate + EPO groups, which was in accordance with the expression of the RhoA mRNA (Fig. 2). However, compared with the control group, the glutamate increased active RhoA expression in cultured retinal explants $(\mathrm{P}<0.05$; Fig. 2$)$. The protein expression of active RhoA in the glutamate + EPO group was significantly lower than that in the simple glutamate group ( $\mathrm{P}<0.05$; Fig. 2). Compared with the control group, the glutamate increased ROCK1 and ROCK2 expression in
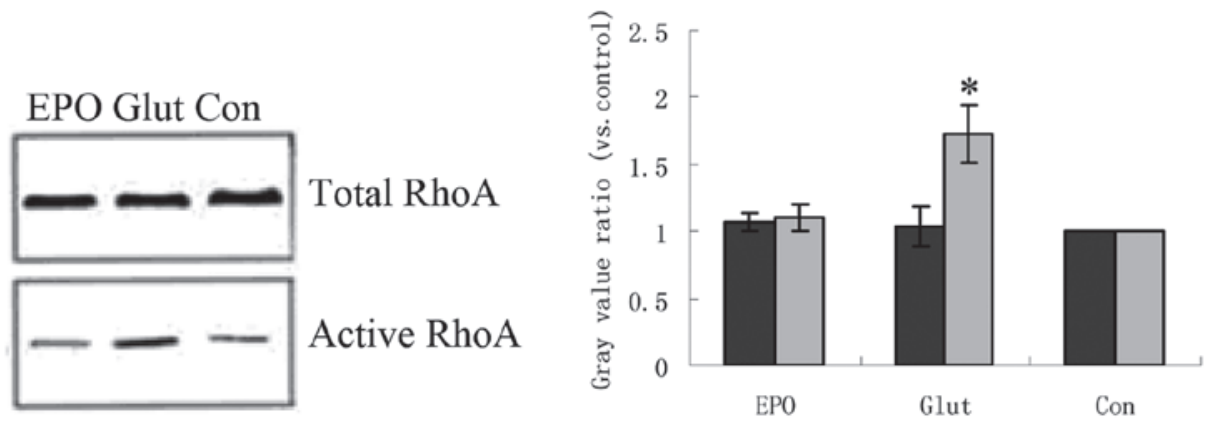

Total RhoA

口Active RhoA

EPO

Glut

Con

Figure 2. Representative western blots showing the expression regulation of total and active RhoA in retinal explants after $72 \mathrm{~h}$ culture with 5 mM/1 glutamate and $6.0 \mathrm{U} / \mathrm{ml}$ EPO. The protein expression of total-RhoA did not differ substantially between the groups. The glutamate increased active RhoA expression in the cultured retinal explants. The protein expression of active RhoA in the EPO group was significantly lower than that in the simple glutamate group, and similar to that in the control group. EPO: $6 \mathrm{U} / \mathrm{ml} \mathrm{EPO}+5 \mathrm{mM} / 1$ glutamate culture group; Glut: $5 \mathrm{mM} / 1$ glutamate culture group; Con: control group. ${ }^{*} \mathrm{P}<0.05$ compared with EPO and control groups. EPO, erythropoietin.
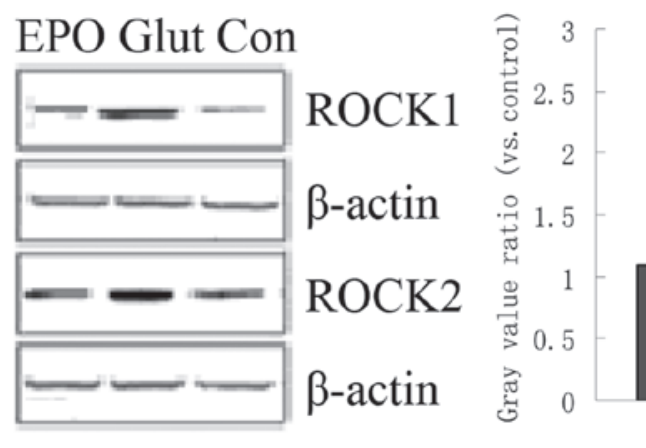

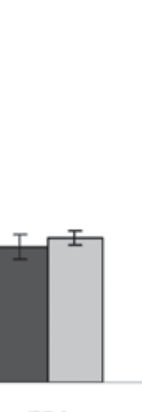

EP0

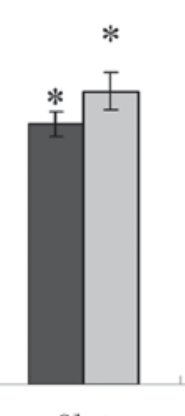

Glut $\square$ ROCK1

$\square$ ROCK2

Figure 3. Representative western blots showing the expression regulation of ROCK1 and ROCK2 in retinal explants after 72 h culture with 5 mM/l glutamate and $6.0 \mathrm{U} / \mathrm{ml}$ EPO. The glutamate increased ROCK1 and ROCK2 expression in cultured retinal explants. The protein expression of ROCK1 and ROCK2 in the EPO group was significantly lower than that in the simple glutamate group. EPO: $6 \mathrm{U} / \mathrm{ml} \mathrm{EPO} \mathrm{+} 5 \mathrm{mM} / 1$ glutamate culture group; Glut: 5 mM/1 glutamate culture group; Con: control group. ${ }^{*} \mathrm{P}<0.05$ compared with EPO group and control group. ROCK, Rho-associated kinase; EPO, erythropoietin. 
cultured retinal explants $(\mathrm{P}<0.05$; Fig. 3). The protein expression of ROCK1 and ROCK2 in the glutamate + EPO group was significantly lower than that in the simple glutamate group ( $\mathrm{P}<0.05$; Fig. 3), and similar to that in the control group.

\section{Discussion}

A number of studies have confirmed that Rho and its associated signaling molecules are involved in and mediate the biological processes of axon regeneration, extension and fiber projection (28-31). Rho regulates the cell actin cytoskeleton by its downstream effective factor ROCK, which is extensively involved in the biological processes of cell migration, movement, apoptosis, gene transcription and nerve regeneration (32). An important reason that axon regeneration is difficult following CNS damage in adult mammals is the existence of certain growth suppression molecules in the damaged environment. Three types of molecules derived from myelin which can suppress axon growth have been identified thus far: Nogo-A, myelin-associated glycoprotein (MAG) and oligodendrocyte-myelin glycoprotein (Omgp) (1). Previous studies indicate that Nogo-A, MAG and Omgp may activate Rho by common or different pathways and subsequently cause growth cone collapse $(33,34)$.

Our previous studies demonstrated that EPO had a neuroprotective effect in vivo (15) and a neurite outgrowth promotion effect on retinal neurons in vitro (23). However, the mechanism of the axonal regeneration effect of EPO on retinal neurons has not been fully clarified. A previous study has shown that EPO promotes the regeneration of adult CNS neurons via activation of the JAK2/STAT3 and PI3K/AKT pathways, and that EPO-facilitated neuritogenesis is paralleled by the upregulation of $\mathrm{Bcl}-\mathrm{X}(\mathrm{L})$ (35). However, the induced expression of $\mathrm{Bcl}-\mathrm{X}(\mathrm{L})$ alone cannot completely neutralize the inhibition of axonal growth (36). Thus, the axonal regeneration mechanism of EPO in damaged RGCs in adult rats may also involve other signaling pathways or factors. To gain a deeper understanding of the EPO-dependent axonal regeneration process, we studied the effects of EPO on RhoA/ROCK expression in rat retinal explants cultured with $5 \mathrm{mM} / \mathrm{l}$ glutamate. Our results show that glutamate increased the active RhoA, ROCK1 and ROCK2 expression in cultured retinal explants, and that the expression of active RhoA, ROCK1 and ROCK2 in the glutamate + EPO group was significantly lower than that in the simple glutamate group, and similar to that in the control group. This suggests that EPO downregulated the active RhoA, ROCK1 and ROCK2 expression in retinal explants cultured with glutamate.

There were a few limitations in our study. Firstly, the present study did not explore the axonal regeneration of retinal neurons, making it difficult to determine the relationship between the RhoA/ROCK expression and axonal regeneration. Secondly, the study did not determine where the active RhoA, ROCK1 and ROCK2 expression occurred in the cultured retinal explants. Further investigations are required to demonstrate the locations of active RhoA, ROCK1 and ROCK 2 expression and the correlation between RhoA/ROCK expression and the axonal regeneration of retinal neurons.

In conclusion, our results suggest that glutamate increases the active RhoA, ROCK1 and ROCK2 expression in cultured retinal explants, and that EPO downregulates the active RhoA, ROCK1 and ROCK2 expression in retinal explants cultured with glutamate.

\section{Acknowledgements}

This study was funded by the National Natural Science Foundation of China (Nos. 81070728 and 81000373), Shanghai Natural Science Foundation (Nos. 08ZR1413900 and 11ZR1422000), Shanghai Municipal Education Committee Project (No. 10YZ38), Shanghai leading Academic Discipline Project (No. S30205) and Shanghai 'Science and Technology Innovation Action Plan' Basic Research Key Project (Nos. 11JC1407700 and 11JC1407701).

\section{References}

1. Tan HB, Zhong YS, Cheng Y and Shen X: Rho/ROCK pathway and neural regeneration: a potential therapeutic target for central nervous system and optic nerve damage. Int J Ophthalmol 4: 652-657, 2011.

2. Lingor P, Teusch N, Schwarz K, Mueller R, Mack H, Bähr M and Mueller BK: Inhibition of Rho kinase (ROCK) increases neurite outgrowth on chondroitin sulphate proteoglycan in vitro and axonal regeneration in the adult optic nerve in vivo. J Neurochem 103: 181-189, 2007

3. Lingor P, Tönges L, Pieper N, Bermel C, Barski E, Planchamp V and Bähr M: ROCK inhibition and CNTF interact on intrinsic signalling pathways and differentially regulate survival and regeneration in retinal ganglion cells. Brain 131 (Pt 1): 250-263, 2008.

4. Zhang Z, Ottens AK, Larner SF, Kobeissy FH, Williams ML, Hayes RL and Wang KK: Direct Rho-associated kinase inhibition [correction of inhibition] induces cofilin dephosphorylation and neurite outgrowth in PC-12 cells. Cell Mol Biol Lett 11: 12-29, 2006.

5. Dergham P, Ellezam B, Essagian C, Avedissian H, Lubell WD and McKerracher L: Rho signaling pathway targeted to promote spinal cord repair. J Neurosci 22: 6570-6577, 2002.

6. Chan CC, Khodarahmi K, Liu J, Sutherland D, Oschipok LW, Steeves JD and Tetzlaff W: Dose-dependent beneficial and detrimental effects of ROCK inhibitor Y27632 on axonal sprouting and functional recovery after rat spinal cord injury. Exp Neurol 196: 352-364, 2005.

7. Sakanaka M, Wen TC, Matsuda S, Masuda S, Morishita E, Nagao $M$ and Sasaki R: In vivo evidence that erythropoietin protects neurons from ischemic damage. Proc Natl Acad Sci USA 95: 4635-4640, 1998.

8. Bernaudin M, Marti HH, Roussel S, Divoux D, Nouvelot A, Mackenzie ET and Petit E: A potential role for erythropoietin in focal permanent cerebral ischemia in mice. J Cereb Blood Flow Metab 19: 643-651, 1999.

9. Brines ML, Ghezzi P, Keenan S, Agnello D, de Lanerolle NC, Cerami C, Itri LM and Cerami A: Erythropoietin crosses the blood-brain barrier to protect against experimental brain injury. Proc Natl Acad Sci USA 97: 10526-10531, 2000.

10. Calapai G, Marciano MC, Corica F, Allegra A,Parisi A, Frisina N, Caputi AP and Buemi M: Erythropoietin protects against brain ischemic injury by inhibition of nitric oxide formation. Eur J Pharmacol 401: 349-356, 2000.

11. Celik M, Gökmen N, Erbayraktar S, Akhisaroglu M, Konakc S, Ulukus C, Genc S, Genc K, Sagiroglu E, Cerami A and Brines M: Erythropoietin prevents motor neuron apoptosis and neurologic disability in experimental spinal cord ischemic injury. Proc Natl Acad Sci USA 99: 2258-2263, 2002.

12. Gorio A, Gökmen N, Erbayraktar S, Yilmaz O, Madaschi L, Cichetti C, Di Giulio AM, Vardar E, Cerami A and Brines M: Recombinant human erythropoietin counteracts secondary injury and markedly enhances neurological recovery from experimental spinal cord trauma. Proc Natl Acad Sci USA 99: 9450-9455, 2002.

13. Sekiguchi Y, Kikuchi S, Myers RR and Campna WM: ISSLS prize winner: erythropoietin inhibits spinal neuronal apoptosis and pain following nerve root crush. Spine 28: 2577-2584, 2003. 
14. Tsai JC, Wu L, Worgul B, Forbes M and Cao J: Intravitreal administration of erythropoietin and preservation of retinal ganglion cells in an experimental rat model of glaucoma. Curr Eye Res 30: 1025-1031, 2005.

15. Zhong YS, Liu XH, Cheng Y and Min YJ: Erythropoietin with retrobulbar administration protects retinal ganglion cells from acute elevated intraocular pressure in rats. J Ocular Pharmacol Ther 24: 453-459, 2008.

16. Weishaupt JH, Rohde G, Pölking E, Siren AL, Ehrenreich H and Bähr M: Effect of erythropoietin axotomy-induced apoptosis in rat retinal ganglion cells. Invest Ophthalmol Vis Sci 45: 1514-1522, 2004

17. Kilic Ü, Kilic E, Soliz J, Bassetti Cl, Gassmann M and Hermann DM: Erythropoietin protects from axotomy-induced degeneration of retinal ganglion cells by activating ERK-1/-2. FASEB J 19: 249-251, 2005.

18. Junk AK, Mammis A, Savitz SI , Singh M, Roth S, Malhotra S, Rosenbaum PS, Cerami A, Brines M and Rosenbaum DM: Erythropoietin administration protects retinal neurons from acute ischemia reperfusion injury. Proc Natl Acad Sci USA 99: 10659-10664, 2002.

19. King CE, Rodger J, Bartlett C, Esmaili T, Dunlop SA and Beazley LD: Erythropoietin is both neuroprotective and neuroregenerative following optic nerve transection. Exp Neurol 205: 48-55, 2007.

20. Pacary E, Tixier E, Coulet F, Roussel S, Petit E and Bernaudin M Crosstalk between HIF-1 and ROCK pathways in neuronal differentiation of mesenchymal stem cells, neurospheres and in PC12 neurite outgrowth. Mol Cell Neurosci 35: 409-423, 2007.

21. Romijn HJ: Development and advantages of serum-free, chemically defined nutrient media for culturing of nerve tissue. Biol Cell 63: 263-268, 1988.

22. Caffé AR, Ahuja P, Holmqvist B, Azadi S, Forsell J, Holmqvist I, Söderpalm AK and van Veen T: Mouse retina explants after long-term culture in serum free medium. J Chem Neuroanat 22: 263-273, 2001

23. Zhong Y, Yao H, Deng L, Cheng Y and Zhou X: Promotion of neurite outgrowth and protective effect of erythropoietin on the retinal neurons of rats. Graefes Arch Clin Exp Ophthalmol 245: 1859-1867, 2007.

24. Kim BK, Kim HM, Chung KS, Kim DM, Park SK, Song A, Won KJ, Lee K, Oh YK, Lee K, et al: Upregulation of RhoB via c-Jun $\mathrm{N}$-terminal kinase signaling induces apoptosis of the human gastric carcinoma NUGC-3 cells treated with NSC12618. Carcinogenesis 32: 254-261, 2011.

25. Nakamura M, Nagano T, Chikama T and Nishida T: Role of the small GTP-binding protein Rho in epithelial cell migration in the rabbit cornea. Invest Ophthalmol Vis Sci 42: 941-947, 2001.
26. Dubreuil CI, Winton MJ and McKerracher L: Rho activation patterns after spinal cord injury and the role of activated Rho in apoptosis in the central nervous system. J Cell Biol 162: 233-243, 2003.

27. Ahmed Z, Suggate EL, Brown ER, Dent RG, Armstrong SJ, Barrett LB, Berry M and Logan A: Schwann cell-derived factorinduced modulation of the NgR/p75NTR/EGFR axis disinhibits axon growth through CNS myelin in vivo and in vitro. Brain 129 (Pt 6): 1517-1533, 2006.

28. Sivasankaran R, Pei J, Wang KC, Zhang YP, Shields CB, Xu XM and $\mathrm{He} \mathrm{Z}$ : PKC mediates inhibitory effects of myelin and chondroitin sulfate proteoglycans on axonal regeneration. Nat Neurosci 7: 261-268, 2004

29. Zhou FQ, Walzer M, Wu YH, Zhou J, Dedhar S and Snider WD: Neurotrophins support regenerative axon assembly over CSPGs by an ECM-integrin-independent mechanism. J Cell Sci 119 (Pt 13): 2787-2796, 2006.

30. Douglas MR, Morrison KC, Jacques SJ, Leadbeater WE, Gonzalez AM, Berry M, Logan A and Ahmed Z: Off-target effects of epidermal growth factor receptor antagonists mediate retinal ganglion cell disinhibited axon growth. Brain 132 (Pt 11): 3102-3121, 2009.

31. Duffy P, Schmandke A, Schmandke A, Sigworth J, Narumiya S, Cafferty WB and Strittmatter SM: Rho-associated kinase II (ROCKII) limits axonal growth after trauma within the adult mouse spinal cord. J Neurosci 29: 15266-15276, 2009.

32. Bhadriraju K, Yang M, Alom Ruiz S, Pirone D, Tan J and Chen CS: Activation of ROCK by RhoA is regulated by cell adhesion, shape, and cytoskeletal tension. Exp Cell Res 313: 3616-3623, 2007.

33. Schimchowitsch S and Cassel JC: Polyamine and aminoguanidine treatments to promote structural and functional recovery in the adult mammalian brain after injury: a brief literature review and preliminary data about their combined administration. J Physiol Paris 99: 221-231, 2006.

34. Schweigreiter R, Walmsley AR, Niederöst B, Zimmermann DR, Oertle T, Casademunt E, Frentzel S, Dechant G, Mir A and Bandtlow CE: Versican V2 and the central inhibitory domain of Nogo-A inhibit neurite growth via p75NTR/NgR-independent pathways that converge at RhoA. Mol Cell Neurosci 27: 163-174, 2004.

35. Kretz A, Happold CJ, Marticke JK and Isenmann S: Erythropoietin promotes regeneration of adult CNS neurons via Jak2/ Stat 3 and PI3K/AKT pathway activation. Mol Cell Neurosci 29: 569-579, 2005

36. Dietz GP, Dietz B and Bähr M: Bcl-x(L) increases axonal numbers but not axonal elongation from rat retinal explants. Brain Res Bull 70: 117-123, 2006. 